Page 1 of 24- Word Count: 4,844

\title{
Examining the issue of centralization and decentralization in the development of soft and hard energy path in the developing world
}

\author{
Muhammad Salar Khan \\ George Mason University
}

\begin{abstract}
A reliable and affordable energy supply is a fundamental prerequisite for reducing poverty, promoting investment, and boosting economic growth in the developing world. Among the different challenges that developing countries face, chronic energy crises are harrowing. The crises result from the unsatisfactory state of the central grid, a misguided energy mix, and illinformed policies, among other things. The possibility of solving energy crises through a variety of alternative solutions is worth exploring. This review discusses two paths of energy development side by side: a traditional "hard" path of energy development (i.e., central grid extension powered by fossil fuels and nuclear energy expansion) and a relatively recent "soft" path of energy development, which is based on energy conservation and the deployment of renewable energy resources. This paper focuses on one central axis of the discussion: centralization vs. decentralization. This discussion, in turn, has technological,
\end{abstract} economic/business, and political dimensions. Finally, the paper discusses the significance of the debate from meeting the developing world's energy demands. The paper intends not to prefer one or another path of energy development, nor it gives recommendations on diffusing or adopting those development paths. Instead, it explores the literature's central arguments that might help frame the questions for further research. While this debate could be used to ask interesting questions that might help solve the energy crisis in the developing world, the 
Page 2 of 24- Word Count: 4,844

discussion informs countries to advance policies specific to their circumstances under the umbrella of a sound and thoughtful energy productivity policy framework.

Keywords: Soft energy; Hard energy; Decentralization; Centralization; Sustainable systems;

Developing world

A reliable and affordable energy supply is a fundamental prerequisite for reducing poverty, promoting investment, and boosting economic growth in the developing world. Among different challenges that the developing countries face, chronic energy crises are harrowing.

According to the International Energy Agency (2017), about 1.1 billion people in the world did not have access to electricity in 2016. ${ }^{\mathrm{i}}$ Globally, sub-Saharan Africa, India, and other developing Asia are the least electrified regions. ${ }^{\text {ii }}$ Among the least electrified areas, rural areas are even worse. Unfortunately, 'electrified' villages and urban cities also face blackouts and brownouts. Besides a high reliance on an irrational and increasingly unaffordable energy mix, central grids in these regions are old, rusted, and feeble. ${ }^{\text {iii }}$ This unsatisfactory state of the central grid, coupled with the misguided energy mix, also exacerbates the developing world's already serious environmental problems, manifesting in low air quality and unsafe drinking water. On top, states' budgets in developing countries are inadequate too. Highly subsidized and politically regulated electric tariffs hardly cover the operational costs of electricity systems. Given these circumstances, the possibility of electrification through a variety of alternative solutions is worth exploring. This leads me to analyze two paths of energy development side by side: a traditional "hard" path of energy development (i.e. central grid extension powered by fossil fuels and nuclear energy expansion) and a relatively recent "soft" path of energy development, which is based on energy conservation and the deployment of renewable energy resources. This review 
Page 3 of 24- Word Count: 4,844

paper compares and contrasts the role of soft versus hard energy technologies in ameliorating energy crises.

The paper first discusses a brief history of soft versus hard technologies debate and then major contentions underlying the framework's discussion. This debate revolves around many dimensions, including the size of facilities and the degree of centralization, among many other things. This paper focuses on one major axis of the debate: centralization vs. decentralization. This debate, in turn, has technological, economic/business, and political dimensions. Relevant literature is used to synthesize arguments. Finally, the paper discusses the significance of the debate from meeting the energy demands of the developing world. The paper intends not to prefer one or another path of energy development, nor it gives recommendations on diffusing or adopting those development paths. Instead, it explores the literature's central arguments that might help frame the questions for further research.

\section{Soft vs. Hard Paths:}

As Lovins defined, ${ }^{\text {iv }}$ soft path broadly consists of renewable energy resources and energy conservation (or "energy efficiency"). In contrast, a hard path epitomizes a centralized energy system, which is mostly powered by fossil fuels. Within a centralized energy system, giant power plants running in central locations usually generate energy, and then transmission and distribution networks transmit this energy to consumers. This means a centralized system has three significant components: generation, transmission, and distribution. Alanne and Saari paints an example of a centralized energy system in the following image: ${ }^{\mathrm{v}}$ 
Page 4 of 24- Word Count: 4,844

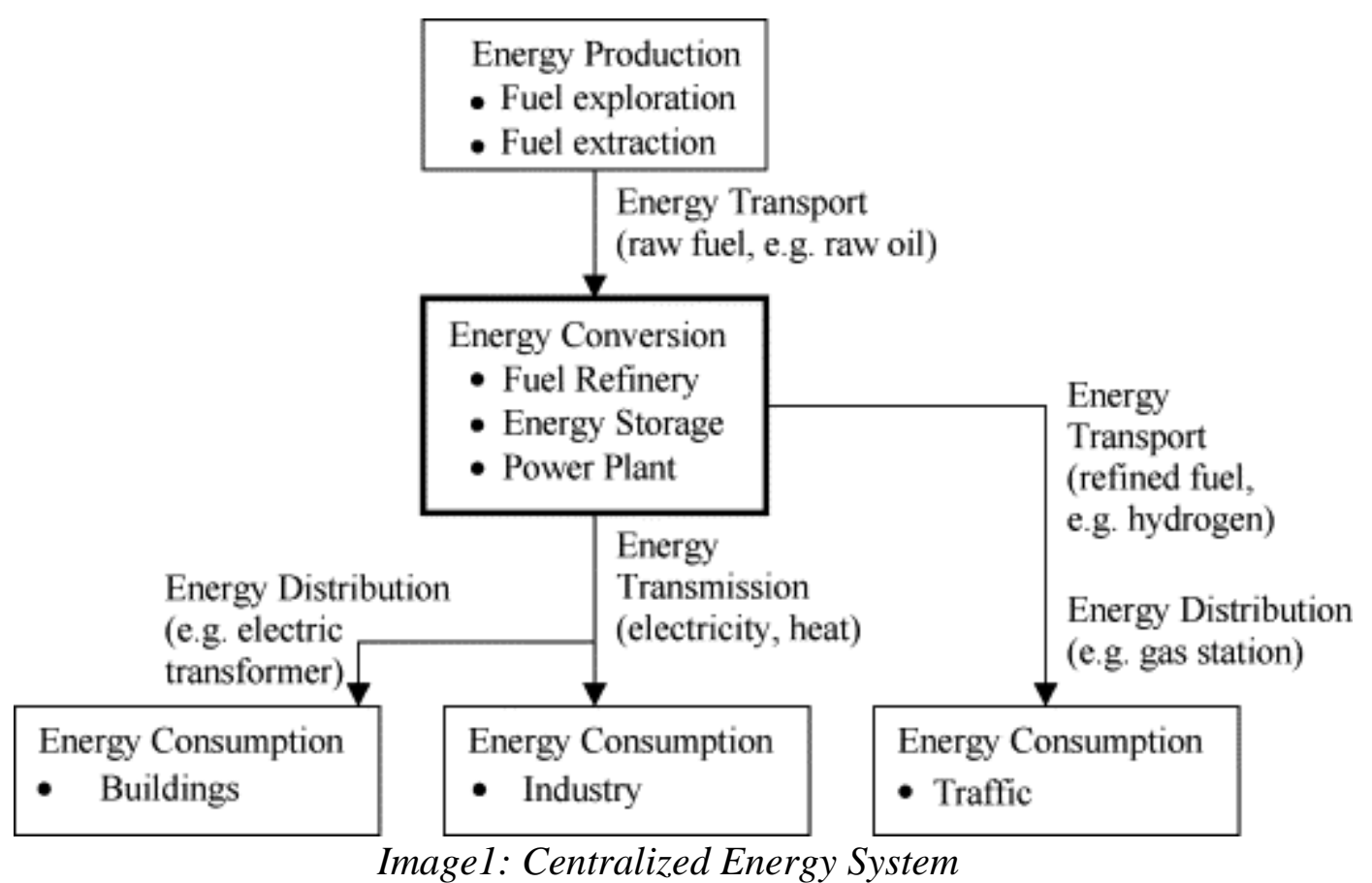

In contrast, the Soft path is typified by a distributed energy system. Since energy is produced and consumed locally, a distributed system does not require big transmission networks. Therefore, a distributed system usually has two big components: generation and distribution. Ackermann, Pepermans, and their colleagues discuss in length the matter of definition of both these systems. ${ }^{\mathrm{vi}}$ Ackermann and his colleagues assert factors including purpose, scale, setting, delivery, technology, modus operandi, environmental impact, possession, and diffusion of distributed generation should dictate the basis of definition. Using this scheme, a distributed energy system or soft path constitutes small-scale (under $200 \mathrm{kWe}$ ) energy production and conversion units that are put in proximity with consumption point for use by a limited number of people. ${ }^{\text {vii }}$ Usually, decentralized or distributed are independent and autonomous. Alaane and Saari draw an example of a "standalone" distributed energy system in the following image: viii 
Page 5 of 24- Word Count: 4,844

Local energy consumption (e.g. a block of buildings)
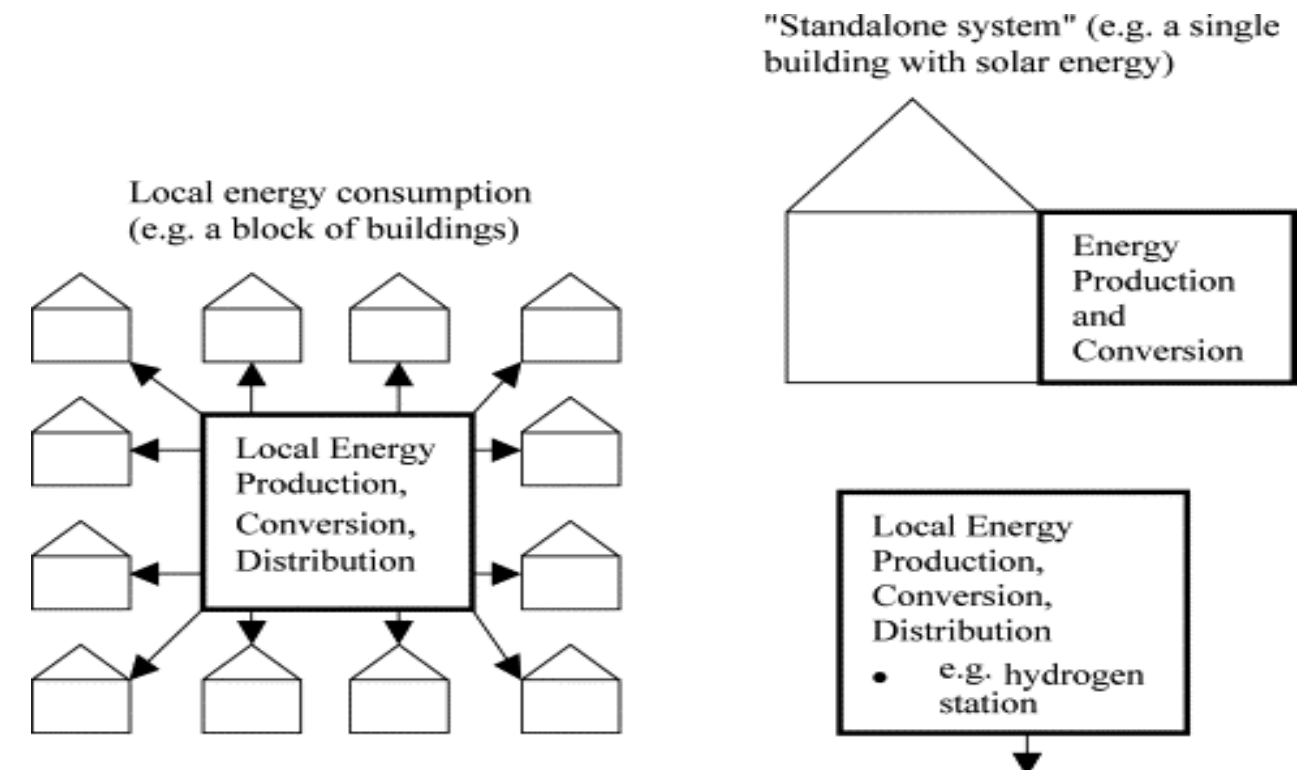

\section{Image2: Distributed Energy System}

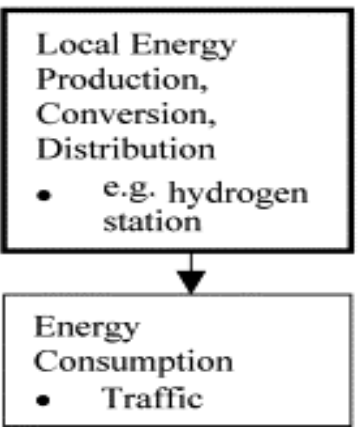

Overall, the literature lacks consensus about the general lexis of distributed, centralized energy systems and their respective soft and hard paths. Therefore, strict or absolute definitions are tantamount to futility or at most reduction. However, there seems consensus on the features that define these paths and systems. Generally, soft technologies (distributed or decentralized) are renewable and small-scale, while hard technologies (centralized) are considered nonrenewable and large-scale. ${ }^{\text {ix }}$ Soft technologies comprise small solar panels, wind power plants, hydroelectric plants, off-grid micro-technologies, biofuels, and liquid fuels.

In contrast, hard technologies include thermal power plants (based on fossil fuels), coal power plants, nuclear power plants (based on fission and fusion), and large-scale solar power plants. The distinction between "hard" and "soft" technologies get complicated at times. For example, traditional hydroelectric power plants are generally classified as soft even though they are large size in most of the cases. Likewise, large-scale solar power plants are renewables; however, they are classified as hard technologies. 
Page 6 of 24- Word Count: 4,844

The history of the debate between hard vs. soft energy paths traces back to the mid1970s. While there is a lot of literature on the subject now, the primary literature comes from around that time. Amory B. Lovins, in his 1976 article for Foreign Affairs, pioneered the debate. ${ }^{\mathrm{x}}$ The article was in black and white shortly after the 1973 oil crisis. That was the time when nuclear energy was leading. ${ }^{\mathrm{xi}}$ Besides, the cold war was still hovering. Against this backdrop, Lovins presented a vision for the US's energy strategy. With the US's energy security threatened by the oil market crisis, Lovins proposed that policymakers cut down fossil fuels and nuclear and move towards renewable energy and energy efficiency. This soft energy track, he contended, offered many advantages such as environmental protection, reduced costs, and broader consumer choice. Now four decades later, fluctuating energy dynamics and worldwide urgency to address climate change make the debate of soft vs. hard energy choices all the more imperative, globally. Denis Hayes, and later the Union of Concerned Scientists were other major advocates of the transition to a soft energy path. ${ }^{\text {xi }}$ People against corporations and environmentalists swiftly embraced the soft energy idea based on the belief that the soft technologies are harbingers of a new social order, which would uproot the entrenched corrupt and bureaucratic system. Proponents claim further that soft technologies are resource-efficient, ecologically caring, under individual control, and economical. The aforementioned fervently disputed contentions triggered a harsh response from the supporters of traditional hard technologies. ${ }^{\text {xiii }}$ This group critiqued the decision to go for soft energy technologies because these technologies lacked technical and cost feasibility, equivalent to a massive societal disorder if the soft path failed to deliver.

Lovins' assertion that hard energy technologies must give way to soft technologies come from a detailed cost-benefit analysis of both technologies. He counts the following characteristics of soft energy technologies: ${ }^{x i v}$ 
Page 7 of 24- Word Count: 4,844

a) They rely on the ever-existing renewables such as sun and wind

b) They are diverse so that the entire energy supply is a sum of modest contributions from different sources

c) They are flexible and easy to understand

d) They match in scale and geographic distribution to end-user needs

In short, for Lovins, features like scalability, flexibility, diversity, and renewability characterize soft technologies. Talking about hard technologies, he asserts that a power station is inefficient because it produces a huge amount of waste heat. ${ }^{\mathrm{xv}}$ However, soft technologies, such as solar mini grids, are very efficient. As opposed to capital-intensive hard technologies, soft technologies are simple and have a small unit size, which helps moderate overheads. While hard technologies lead to a lot of energy wastage in the generation, transmission, and distribution of energy resources, soft technologies cause additional savings by abolishing distribution losses. ${ }^{\text {xvi }}$ Moreover, soft technologies also decrease misjudged projections associated with massive power grids. Contrasted with hard technologies, which maximize economic risks to capital in disasters and breakdowns, soft technologies appear reliable by minimizing those risks. In light of these assertions, Lovins' conclusion for a soft paradigm is edifying. For him, the soft path is resilient and stable. "However, the hard path is brittle;"xvii it might fail if technical and social conditions are not met 'continuously' and 'indefinitely.'

Thinking of the energy system as an information system, Alaane and Sari (as cited from Robertson; 2002) list down the drawbacks and benefits of centralized and decentralized energy systems. ${ }^{\text {xviii }}$ 
Page 8 of 24- Word Count: 4,844

\section{Centralized}

\section{Benefits}

- One can find Information easily

- One can place responsibility, management, and expertise easily

- Only a few educated persons needed

-Uniformity
Drawbacks

-Units should be large $\cdot$ Scalability

-Large byinvestments

- 'all the eggs in the same basket'

-Long distances between production and consumption

-Cannot work independently

-Lack of individuality $\bullet$ Flexibility -Inflexibility
-Shared load

-Ability to 'live' in networks -Even distribution of

\section{Benefits}

-Can work independently

-Individuality political, technological, economic, and social resources

-Increased control at the local level

- Not all the eggs in the same basket'
Distributed

Drawbacks

- Information is fragmented

-No uniformity and consistency

-Substantial effort in management and education

The drawbacks of centralized and benefits of distributed in this table are in parallel with the Lovins paradigm. However, Robertson differs from Lovins when he counts the benefits of centralized and drawbacks of the distributed systems. For him, a centralized system is good in terms of expertise, knowledge, and decision making because it facilitates finding information and leads to a clear division of responsibility. As for distributed systems' drawbacks, they are more "fragmented" than centralized, have multiple nodes of information, and require more experts as the decisions are subordinated to local decision-makers.

Lovins did not consider the difficulty and time required to implement some soft technologies; in fact, the implementation could be considerably exhausting. Like the time-tested 
Page 9 of 24- Word Count: 4,844

hard technologies' barriers such as nuclear siting, regulatory issues, and funding issues, soft technologies also need to overcome the institutional obstacles. But Lovins assert that institutional barriers would be comparable. ${ }^{\text {xix }}$ I disagree and suggest that it would be difficult for soft technologies to eliminate the institutional barriers at local, provincial, and national levels because of the limited experience, relative novelty, and strong institutional inertia. Further, it might be true that soft energy technologies better serve the dispersed population in rural areas, but would they meet the energy demands in big cities with crowded areas and commercial buildings. Centralized power plants would be required for industry and commerce. While Lovins and others talk about diseconomies of scale accrued due to centralized grids, they ignore technological innovation in the foreseeable future. For example, Lovins failed to predict and thus consider the falling prices of natural gas due to advanced fracking technologies.

In addition, the 'pro-centralized' literature above overlooked some of the benefits associated with distributed energy, such as the new local market opportunities, increased competition, and the use of local fuels and information networks. Similarly, the 'pro-distributed' literature disregarded the increased need for training, local distribution of emissions, and the potential risk of hazards in consumption location because of additional devices.

Finally, the overwhelming importance of conservation by Lovins and other prodistributed researchers hurt growth in different countries. A growing population coupled with rising growth in the developing world, could still mean mounting demands for energy. If developing countries do not build central grid capacity, this could ultimately exacerbate gaps between the already unbalanced supply and demand. Consequently, they will see additional blackouts, falling industrial growth, and an overall busting economic growth. Government intervention in such an emergency might lead, paradoxically, to an increase in centralization. 
Page 10 of 24- Word Count: 4,844

\section{Centralization vs Decentralization}

The debate of soft vs. hard technologies hinges upon the degree of centralization. Hard technologies are centralized, whereas soft technologies are decentralized. Proponents of soft energy often boast about decentralization. In fact, most of the advantages linked to soft energy technology are largely because of decentralization. Pro-distributed scholars laud decentralization for many of its considerations, including end-use matching, grid interconnection, and environmental impacts, among other things. On the contrary, pro-centralized scholars praise centralization for many other considerations: cost-effectiveness, energy security, huge experience, and historical precedence. This debate between centralized and decentralized energy system cannot be studied in a vacuum. At the heart of this debate is a complex interplay among economic, technological, social, and political factors, as suggested by literature dealing with socio-economic paradigm shifts, ${ }^{\mathrm{xx}}$ national systems of innovation, ${ }^{\mathrm{xxi}}$ and functions of innovation systems. ${ }^{\text {xii }}$ The literature, in general, indicates wide-ranging opinions and differing assertions regarding politics, technology, economics, and other significant considerations relevant to the centralization versus decentralization issue.

Politics is very crucial to the debate about alternative energy. ${ }^{\text {xxii }}$ As a means towards sustainable development, Lafferty would call soft energy development a normative project. ${ }^{\text {xxiv }}$ In a similar vein, Meadowcraft calls it a political project. ${ }^{\mathrm{xxv}}$ Meaning thereby, politics (including state intervention and reforms) play a pivotal role in protecting or exposing one or other energy development paths. Political activism and political dimensions are primarily referred to in the instance of Dutch “energy transition."xxvi Meadowcroft asserts that politicians' and voters' ideas always echo in energy decisions. ${ }^{\text {xxii }}$ For example, Germany's government handing over the renewable energy portfolio to the ministry of the environment led to the uptake of renewable 
Page 11 of 24- Word Count: 4,844

energy. In contrast, except for a handful of policy instruments such as CAFE and RPS, the US political system has favored the hard energy path.

Decision making is a significant political power. While centralized energy systems distillate power in few organizations' hands, a decentralized energy system arguably renders a greater voice to the individuals. In the case of decentralization, "consumers would be given the task to make decisions." ${ }^{\text {xxviii }}$ This warrant a substantial increment in local responsibility regarding political definitions, rules, and laws. However, the consumers might not care to decide for themselves in decentralized energy systems. As the number of operators increase in the energy sector in a decentralized system, problems may occur with bureaucracy. License procedures of implementation of distributed energy technology can be slow and complicated. ${ }^{\text {xxix }}$ Decision making and bureaucracy roles as briefly touched upon above, are a few of the dimensions in political debate. On the one hand, this debate discusses the reforms, subsidies, type of governance, and institutions' role required to prioritize one or other energy development forms. On the other hand, the debate encompasses ownership, individuality, self-determination, energy-sufficiency, energy independence, environmental protection, and climate change as fundamental issues. This review touched upon a few of the facets briefly in the above passages. Overall, I feel soft energy technologies' prospects rose from conception to inception, as evident in the political economy literature. If a meta-analysis of the past four decades' literature is conducted, this claim might be justified.

Like the rearrangement of power and expertise, decentralized energy systems reposition technology as well. Generally, distributed energy generation means local energy conversion. Thus, the technology would focus on utilizing local fuels like biomass and establishing local fuel storage. Since the number of operators increases with decentralization, decentralization leads to 
Page 12 of 24- Word Count: 4,844

an increase in the system's technology amount. Some researchers argue that the vulnerability of the whole system decrease. ${ }^{\mathrm{xxx}}$ Lovins agrees to this, asserting that in addition to decreasing the system's vulnerability, soft technologies by virtue of flexibility, decentralization, and diversity increase the system's resilience and save system capacity. However, critics contend the opposite; they say that because of "fragmented decisions," "lack of local expertise," and relatively "nascent technology," distributed systems are in fact, more subject to the vagaries of nature, thus prone to depriving nations of electricity in harsh climates. ${ }^{\text {xxi }}$ They further argue that soft technologies with/without interconnection might result in voltage collapse, massive voltage variations, system instabilities, and bad protection of the generation equipment. ${ }^{\text {xxii }}$ For example, Bhattacharyya talks about soft technology—distributed generation micro-grid—in Kanaka village, India. ${ }^{\text {xxxiii }}$ Besides frequent spoilage of LED bulbs, inverter and other equipment got damaged because of a lightning strike. This led to the quick outage of the plant. Since there was minimal local capacity, they had to hire an out-of-town electrical engineer.

Another argument relates to the design of soft technologies. Lovins claimed that soft technologies are simpler, ${ }^{\text {xxxiv }}$ and thus could be repaired quickly even by medium-skilled maintenance personnel. However, the actual maintenance experience might not support this claim for small, decentralized energy systems. Bhattacharyya and colleagues did a comparative analysis of different community, public, and private-sponsored distributed energy micro-grids in India. ${ }^{\mathrm{xxv}}$ They found out that at least two models — community-run and public-funded — suffered from repair maintenance issues; either the maintenance was not timely or too challenging to cater to. Thus, soft energy systems may or may not be technologically simple. Even if decentralized systems are simple, the kind of technological development required for integrating the system, improving, operating, and overseeing the system would need skilled staff as required for 
Page 13 of 24- Word Count: 4,844

complex systems. Furthermore, almost all the literature on challenges to the decentralized systems contend that since decentralized technologies would be operated locally, there is even more need for a local capacity building.

In addition to the design, the efficiency of the systems comes into the debate. Generally, the proponents of hard technologies argue that centralized larger plants are efficient as they provide inexpensive power to nations and masses. ${ }^{\text {xxxi }}$ The pro-distributed literature, starting from Lovins and others, claims a lack of evidence for greater technical efficiency in centralized plants. $^{\text {xxxvii }}$ This literature asserts that the complexity of the technologies and all operating requirements lower the system's reliability. Conversely, numerous distributed units could deliver the same level of power and reliability (with a lesser capacity) because the probability of all the plants failing at the same time is low. Interestingly, the IEA outlooks about power plant efficiencies display enhancements over time. ${ }^{\text {xxxiii }}$ These expected enhancements are mostly the result of replacing old plants with new plants that have better efficiencies. In general, the prodistributed literature overlooks details about the efficient power plants such as baseload and intermediate load power plants. Whereas the pro-centralized literature ignores the current highefficiency gains affiliated with soft technologies. It would be interesting if the efficiency argument would still be relevant, particularly when the central power plants take different efficiency measures in response to environmental regulations.

Finally, one last aspect of the technologies is the relative technical lead time. The soft technologies have shorter lead times than complex hard technologies. ${ }^{\text {xxxix }}$ As a result, soft technologies could be developed, demonstrated, and deployed quickly. Thus several approaches might be tested at the same time at low risk. An example of this, Lovins points out that 40 
Page 14 of 24- Word Count: 4,844

percent of homeowners in Vermont retrofitted their homes with wood-burning stoves in three years. $^{\mathrm{xl}}$

All in all, the literature about the technological aspects of the soft vs. hard paths is broad but sketchy. Technological feasibility and technical supremacy of one or another approach largely depend on the assumptions and the contexts the researchers have in mind. There are nuances within hard and soft energy technologies; hydropower might be efficient than wind, and likewise, natural gas might be efficient than coal. Thus, preferring soft technologies over hard technologies and vice versa is an erroneous generalization. In fact, the technologies, and the resulting mix of technologies that countries might witness depend on the economics of technologies as well.

As for the economics of technologies, the research considers factors such as sunk costs, operating costs, maintenance costs, economies of scale, economies of mass production and reliability, etc.

Lovins conducted an economic analysis of soft technologies and all other alternatives. ${ }^{\text {xli }}$ It turned out that soft technologies compared to oil and gas might or might not be cheaper, but they are largely less expensive than the other options one would seek to substitute oil and gas. This study found end-use efficiency improvements to be least expensive, then the soft technologies, followed by synthetic fuels and central electric systems. In recent times, Sivaram concludes that for consumers, the prices of soft technologies were comparable to kerosene and wood-fuel in faroff rural India and sub-Saharan Africa. ${ }^{\text {xlii }}$ Hard technologies proponents assert that hard technologies are less costly because of the economies of scale. ${ }^{\text {xlii }}$ Lovins claims that many of these economies of scale are "outweighed by less tangible but perhaps more important disadvantages and diseconomies." I think both pro-centralized and pro-distributed miss some 
Page 15 of 24- Word Count: 4,844

crucial factors. The pro-centralized literature does not talk much about the natural and artificial constraints to scale. For example, the transmission line capacity might be limited by a particular line voltage. Similarly, the pro-distributed literature does not help on how to acquire some economies of scale.

Other people disagree with the claims of lower cost for soft technologies. Overall, data from the US EIA suggests that the capital investment required to adopt the soft energy path is larger than the capital investment needed for a large energy path. ${ }^{\text {xliv }}$

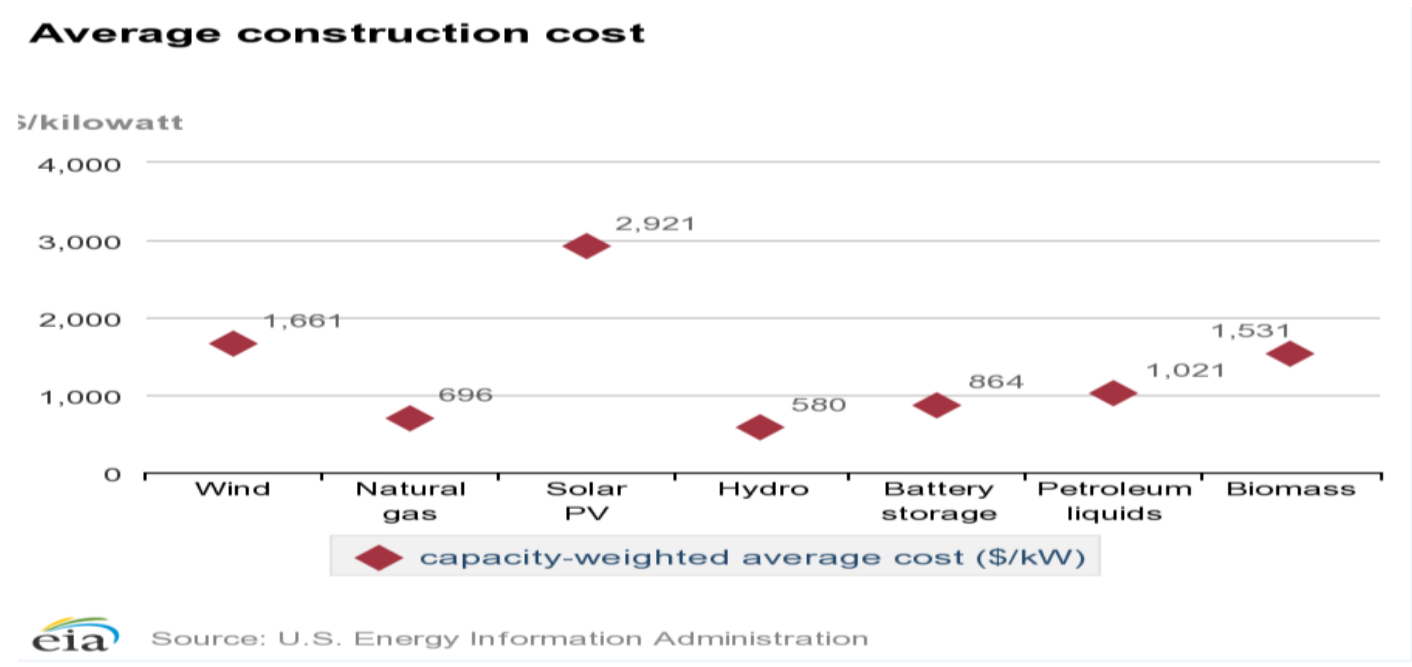

Image3: Average construction cost

Another set of data from the EIA on average power plant operating expenses for major US investor-owned electric utilities (2006 through 2010) indicates hydroelectric the least expensive, while gas turbine, photovoltaic, and wind plants the most costly options. ${ }^{\mathrm{xlv}}$ Research also talks about financial barriers that include low returns on investment, high transaction costs, lack of experience with energy access financing, and the unsuitability of existing credit facilities. ${ }^{\text {xlvi }}$ However, it seems that these researches didn't consider the possibilities of technical breakthroughs that might reduce soft energy costs significantly. 
Page 16 of 24- Word Count: 4,844

While some of these issues, such as lack of experience with energy access financing and unsuitability (unavailability) of existing credit facilities, make sense, other barriers such as low returns on investment and high capital costs are contested. Issues such as transaction costs are very contextual as it depends on a host of factors. Transaction costs might be higher in one setting but could be lower in other. For example, Sivaram talks about the extension of OffGrid Electric $^{x l v i i}$ in two different locations: East Africa (Kenya, Tanzania, and Rwanda) and India. ${ }^{\text {xlviii }}$ The customers had to pay through mobile banking for solar systems. Sivaram contends that the gains are more in East Africa than in India because India regulates mobile banking while East Africa leaves it unregulated (transaction costs were lower in Africa than in India). Secondly, in India, villagers enjoy kerosene subsidies, which keeps its price very low.

Another concern that the research talks about, specifically in the context of the developing world, is the scalability of the soft energy approach, i.e., would it be able to ramp up a generation to suffice nations' energy demands. In this regard, the total costs might increase as the soft energy path incur the costs to use backup energy capacity from a central power system. Also, would individuals be able to raise money for the development of the expensive soft path? Therefore, a lot of research proposes the government to grant subsidies to make soft technologies attractive. ${ }^{\text {xlix }}$ This raises the concern that consumers might end up paying more taxes to support subsidies, which might not be socially optimal. The counterargument is that the centralized energy system is already subsidized. So comparable subsidies to soft technologies will not make any difference to consumers.

Overall, economics studies come up with contradictory results. This might be because of different expectations about future costs. Studies that find hard energy systems to be economical have patterns including overall reliance on status-quo, an assumption about costs' stickiness of 
Page 17 of 24- Word Count: 4,844

energy systems, and psychological negation about the possibility of new forms of alternative energy. On the contrary, studies that find soft energy futures to be cost-effective are hopeful about the cost declines for soft energy systems. Such studies also assume a large degree of consumer determination and initiative to set up and sustain the systems.

Irrespective of the preference for technologies, one powerful argument about the prevalence of soft technologies stem from the universal availability of soft energy resources (renewables) across the world. This fact might be considered to promote an equitable distribution of energy across the globe. Developing countries might take it to their advantage to use the ubiquitous soft in place of hard technologies. However, would they realize this benefit ultimately depend on whether the nations' soft energy systems could be effectively constructed with local capital, labor, skills, and technology? This is yet to explore.

Overall, the debate between soft and hard technologies is conflicting yet interesting. Both sides would probably agree with some blend of energy technologies, either competing or coordinating in the open market. This competition/coordination makes sense. If the world decides to go soft tomorrow, it will need hard technologies today. Although hard technologies might be complicated and challenging to increase the capacity overnight, they have still been running our lives. However, environmental concerns and resource conservation arguments make the quest and development of soft technologies critical. Soft technologies proponents lament about weak competition status by pointing out to the excessive subsidies allotted to hard technologies. Likewise, hard technology proponents point out the dire consequences (such as energy insufficiency) if the soft technologies' subsidies curtailed conventional hard technologies. 
Page 18 of 24- Word Count: 4,844

Overall, there are many paths between hard and soft extremes. Thus, countries would do a cost-benefit analysis of all energy mixes in selecting the optimal combination that best serves their energy needs.

In the developing world, this debate could be used to ask interesting questions that might help solve their energy dilemmas. Developing countries' visions and statements (prepared by their ministries of planning, development, energy, and environment to name one Pillar IV of Vision 2025, ${ }^{1}$ formulated by the Ministry of Planning, Development and Reforms of Pakistan ) in parallel to the United Nations Sustainable Development Goals (SDG\#7) and Sustainable Energy for All (SE4All) initiatives, aim to ensure uninterrupted access to affordable and clean energy for all the citizens. However, the developing world (particularly sub-Saharan Africa, India, Pakistan, and other developing Asia) is yet to achieve its access goal. In a country like Pakistan, with 207 million, the national average electrification rate is $70 \%$. ${ }^{\text {li }}$ This means that 60 million people are not connected to the electric grid. More than $80 \%$ are in rural areas, where a World Bank survey found that 30 to $45 \%$ of households use kerosene as a primary or secondary source of lighting. ${ }^{\text {lii }}$ According to the National Electric Power Regulatory Authority (NEPRA) State of Industry Report 2016, more than 32,000 villages in the country remain without access to the electricity grid, ${ }^{\text {liii }}$ compelling the citizens to use firewood, kerosene, and diesel for meeting their basic needs (i.e., lighting, heating, and cooking). The situation in India is even worst. Over 23 million households in rural India are without electricity. ${ }^{\text {liv }}$

For most of these villages, sparsely distributed populations and remote locations make the electricity grid's expansion financially unviable. Those having access are not in comfort either, as the countries experience massive blackouts. ${ }^{\text {v }}$ 
Page 19 of 24- Word Count: 4,844

This acute energy crisis in those countries results from flawed energy policies pursued for decades, the high cost of generation, and aging and inadequate transmission, among other causes. In addition to transmission losses and distribution thefts, an entrenched bureaucratic culture marked by poor organization, planning, and project implementation among power operating companies only compounds the problem.

Power shortages are also rooted in the irrational and increasingly unaffordable energy mix. High reliance on thermal (which in turn are run by natural gas, oil, or coal) and hydropower ${ }^{\text {lvi }}$ seldom assure a continuous flow of power. ${ }^{\text {lvii }}$ Politicians and policymakers in those countries have made a little real attempt to diversify the nations' energy supplies and to shift dependence from expensive and imported oil ${ }^{\text {lviii }}$ towards potentially cheaper and cleaner resources available in their countries. These countries have high renewable energy potential, which has been elaborated in many studies. ${ }^{\text {lix }}$ For example, energy experts estimate that Pakistan has a total renewable energy potential of about $167.7 \mathrm{GW}$, more than enough to meet its total demand for electricity. ${ }^{1 x}$

Given these countries' situations, and in light of the debate between hard and soft technologies, it would be pertinent to ask how well soft technologies can ease the developing world's energy crisis. Alternatively, under what conditions soft technologies can alleviate the energy crisis. What could the optimal fuel mix in mitigating energy issues? Would providing incentives encourage a shift towards renewable energy resources such as solar, wind, and biogas? What incentives (subsidies) are now in place? What kind of other subsidies might be applied to soft technologies to make them economically competitive, and what would it cost? Alternatively, how would be the impacts of removing any current incentives for conventional 
Page 20 of 24- Word Count: 4,844

power utilities? Would soft technologies be more cost-effective for rural, dispersed areas than urban areas? How would the developing countries finance the soft technologies?

Each question raised above requires a detailed discussion and investigation. In terms of policies, this review's debate informs countries to advance policies specific to their circumstances. These policies should be under the umbrella of a sound and thoughtful energy productivity policy framework. After conducting needs and gaps assessment exercise, such a policy framework should consider move and reliance on a path that produces more output (with the same or less inputs), ameliorate energy security, address environmental degradation, and stimulate economic growth. The policy framework and its successive implementation require careful deliberations by concerned institutions and ministries to advance the policy framework's strategic goals and overcome finance and technology challenges. Finally, developing countries would show their firm resolve in promoting energy productivity reforms (whether it is a move to a soft paradigm or pursuing a diverse paradigm) and eradicating obstacles to successful energy productivity policy implementation. Only then can the world surmount the policy challenge of realizing universal sustainable energy. 
Page 21 of 24- Word Count: 4,844

\title{
References and Endnotes
}

\author{
i International Energy Agency, "Energy Access Outlook" (2017). Accessed May 5, \\ 2018.https://www.iea.org/publications/freepublications/publication/WEO2017SpecialReport_EnergyAccessOutlook \\ .pdf. \\ ii International Energy Agency “Energy Access Outlook” (2017)... \\ iii Norimitsu Onishi "Weak Power Grids in Africa Stunt Economies and Fire Up Tempers." The New York Times, \\ January 19, 2018, sec. World. https://www.nytimes.com/2015/07/03/world/africa/weak-power-grids-in-africa-stunt- \\ economies-and-fire-up-tempers.html. \\ iv Lovins, Amory B. “Energy Strategy: The Road Not Taken?” Foreign Affairs, October 1, 1976. \\ https://www.foreignaffairs.com/articles/united-states/1976-10-01/energy-strategy-road-not-taken.
}

" Alanne, Kari, and Arto Saari. "Distributed Energy Generation and Sustainable Development." Renewable and Sustainable Energy Reviews 10, no. 6 (December 1, 2006): 539-58. https://doi.org/10.1016/j.rser.2004.11.004.

vi Ackermann, Thomas, Göran Andersson, and Lennart Söder. "Distributed Generation: A definition.” Electric Power Systems Research 57, no. 3 (April 20, 2001): 195-204. https://doi.org/10.1016/S0378-7796(01)00101-8.

Pepermans, G., J. Driesen, D. Haeseldonckx, R. Belmans, and W. D'haeseleer. "Distributed Generation: Definition, Benefits and Issues." Energy Policy 33, no. 6 (April 1, 2005): 787-98. https://doi.org/10.1016/j.enpol.2003.10.004.

${ }^{\text {vii }}$ Alanne, Kari, and Arto Saari. “Distributed Energy Generation and Sustainable Development.” (2006).

viii Ibid.

ix Marcus, Gail H.“Soft versus Hard Energy Paths.” Report No. 81-94 SPR. (1981). Accessed May 5, 2018. https://www.everycrsreport.com/files/19810301_81-94_b3c1afcd8da5b309c64211adb317e64184a17363.pdf.

${ }^{x}$ Lovins, Amory B. “Energy Strategy: The Road Not Taken?” Foreign Affairs (1976).

${ }^{x i}$ Energy Information Administration, "U.S. Commercial Nuclear Capacity Comes from Reactors Built Primarily between 1970 and 1990 - Today in Energy - U.S. EIA.” Accessed May 5, 2018.

https://www.eia.gov/todayinenergy/detail.php?id=2030.

xii Hayes, Denis "Rays of Hope: The Transition to a Post-Petroleum World." (1977). Norton Worldwatch Books. P.250

Marcus, Gail H.“Soft versus Hard Energy Paths.” Report No. 81-94 SPR. (1981).

xiii See for example, “Alternative Long-Range Energy Strategies Submittal of the Senate Committee on Interior and Insular Affairs to the Senate Budget Committee pursuant to Section 301(c) of the Congressional Budget Act." (94 ${ }^{\text {th }}$ Congress, $2^{\text {nd }}$ session, 1976). Accessed May 5, 2018. http://ufdc.ufl.edu/AA00022527/00001/1j.

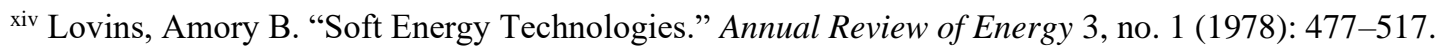
https://doi.org/10.1146/annurev.eg.03.110178.002401.

Lovins, Amory B. “Energy Strategy: The Road Not Taken?” Foreign Affairs (1976).

Lovins, Amory B. "Soft energy paths: toward a durable peace." United States: N. p., (1977). Web.

${ }^{x v}$ Ibid.

xvi Perelman, Lewis, "Shifting Security Paradigms: Towards Resilience" as appeared in Critical Thinking: Moving from Infrastructure Protection to Infrastructure Resilience. CIPP George Mason University (2007). P.25Accessed 
Page 22 of 24- Word Count: 4,844

May 5, 2018.

http://citeseerx.ist.psu.edu/viewdoc/download;jsessionid=C359CF09E0E785A43C91C0A1871A9B4E?doi=10.1.1.1 69.9384\&rep=rep1\&type=pdf.

xvii Ibid. P.25

xviii Alanne, Kari, and Arto Saari. "Distributed Energy Generation and Sustainable Development." Renewable and Sustainable Energy Reviews, (2006).

J. Robertson - Centralised or Decentralised authoring?

- KM Column - April 2002

xix Lovins, Amory B. “Energy Strategy: The Road Not Taken?” Foreign Affairs (1976).

xx Dosi, Giovanni, “Technological paradigms and technological trajectories.” Research Policy (1982). Accessed May 6, 2018. https://ac.els-cdn.com/0048733382900166/1-s2.0-0048733382900166-main.pdf?_tid=bf13d3e2-f5e74ed8-8739-182a1c16d0da\&acdnat=1525571612_b133f4ea990b6fff620c84d0fc6e6a4a.

Perez, C. Technological Revolutions and Financial Capital. Edward Elgar Publishing, 2003.

${ }^{x x i}$ Edquist, Charles. "Reflections on the Systems of Innovation Approach." Science and Public Policy 31, no. 6 (December 1, 2004): 485-89. https://doi.org/10.3152/147154304781779741.

${ }^{\text {xxii }}$ Hekkert,M, R. Suurs, S. Negro, S. Kuhlmann, R. Smits, "Functions of innovation systems: A new approach for analysing technological change" Technological Forecasting \& Social Change, 74 (4) (2007), Accessed May 6, 2018. https://ac.els-cdn.com/S0040162506000564/1-s2.0-S0040162506000564-main.pdf?_tid=d87378ff-a829491d-9239-71fba79c7acc\&acdnat=1525571971_ff531dd42555f065e321c69abe0ef559.

Coombs, Rod. Technology and the Market: Demand, Users and Innovation. Edward Elgar Publishing, 2001.

xxiii Meadowcroft, James. "What about the Politics? Sustainable Development, Transition Management, and Long Term Energy Transitions.” Policy Sciences 42, no. 4 (November 1, 2009): 323. https://doi.org/10.1007/s11077-0099097-z.

Andy, Stirling. "Deliberate Futures: Precaution and Progress in Social Choice of Sustainable Technology." Sustainable Development 15, no. 5 (September 1, 2007): 286-95. https://doi.org/10.1002/sd.347.

Lehtonen, Markku, and Florian Kern. “Deliberative Socio-Technical Transitions.” In Energy for the Future, $103-22$. Energy, Climate and the Environment Series. Palgrave Macmillan, London, 2009.

https://doi.org/10.1057/9780230235441_7.

xxiv Lafferty, William M. "The Politics of Sustainable Development: Global Norms for National Implementation." Environmental Politics 5, no. 2 (June 1, 1996): 185-208. https://doi.org/10.1080/09644019608414261.

${ }^{x x v}$ Meadowcroft, James. "Who Is in Charge Here? Governance for Sustainable Development in a Complex World*." Journal of Environmental Policy \& Planning 9, no. 3-4 (September 1, 2007): 299-314. https://doi.org/10.1080/15239080701631544.

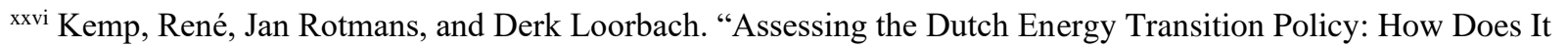
Deal with Dilemmas of Managing Transitions?" Journal of Environmental Policy \& Planning 9, no. 3-4 (September 1, 2007): 315-31. https://doi.org/10.1080/15239080701622816.

Kern, Florian, and Adrian Smith. "Restructuring Energy Systems for Sustainability? Energy Transition Policy in the Netherlands.” Energy Policy, Transition towards Sustainable Energy Systems, 36, no. 11 (November 1, 2008): 4093-4103. https://doi.org/10.1016/j.enpol.2008.06.018. 
Page 23 of 24- Word Count: 4,844

Kern, Florian, and Michael Howlett. "Implementing Transition Management as Policy Reforms: A Case Study of the Dutch Energy Sector.” Policy Sciences 42, no. 4 (November 1, 2009): 391. https://doi.org/10.1007/s11077-0099099-x.

${ }^{x x v i i}$ Meadowcroft, James. "Engaging with the Politics of Sustainability Transitions." Environmental Innovation and Societal Transitions 1, no. 1 (June 1, 2011): 70-75. https://doi.org/10.1016/j.eist.2011.02.003.

xxviii Alanne, Kari, and Arto Saari. "Distributed Energy Generation and Sustainable Development." Renewable and Sustainable Energy Reviews, (2006).

xxix Ibid

${ }^{\mathrm{xxx}}$ Ibid

xxxi Ibid

xxxii Lopes, J. A. Peças, N. Hatziargyriou, J. Mutale, P. Djapic, and N. Jenkins. "Integrating Distributed Generation into Electric Power Systems: A Review of Drivers, Challenges and Opportunities." Electric Power Systems Research, Distributed Generation, 77, no. 9 (July 1, 2007): 1189-1203. https://doi.org/10.1016/j.epsr.2006.08.016.

xxxiii Bhattacharyya, Subhes C., and Debajit Palit. "Mini-Grid Based off-Grid Electrification to Enhance Electricity Access in Developing Countries: What Policies May Be Required?” Energy Policy 94 (July 1, 2016 ): 166-78. https://doi.org/10.1016/j.enpol.2016.04.010.

xxxiv Lovins, Amory B. “Energy Strategy: The Road Not Taken?” Foreign Affairs

${ }^{\text {xxxv }}$ Bhattacharyya, Subhes C., and Debajit Palit. "Mini-Grid Based off-Grid Electrification to Enhance Electricity Access in Developing Countries. (2016).

xxxvi “Electricity Generation.” IER. Accessed May 6, 2018. http://instituteforenergyresearch.org/electricitygeneration.

xxxvii Lovins, Amory B. “Energy Strategy: The Road Not Taken?” Foreign Affairs

xxxviii International Energy Agency, “World Energy Outlook 2017.” Accessed May 6, 2018.

https://www.iea.org/weo2017/.

xxxix Marcus, Gail H.“Soft versus Hard Energy Paths.” Report No. 81-94 SPR. (1981).

${ }^{x l}$ Ibid

xli Lovins, Amory B. “Soft Energy Technologies.” Annual Review of Energy 3, no. 1 (1978): $477-517$.

xlii Sivaram, Varun, "Taming the Sun” Innovations to Harness Solar Energy and Power the Planet. The MIT Press (2018).

xliii "Power Pooling in Electric Power Generation." (1981). Accessed May 6, 2018.

http://warrington.ufl.edu/centers/purc/purcdocs/papers/8109_Howorka_Econometric_Estimates_of.pdf.

“Power Systems of the Future." (2016). Accessed May 6, 2018.

https://arxiv.org/ftp/physics/papers/0304/0304116.pdf.

${ }^{x l i v}$ EIA, "Electricity Generator Cost Data from Survey Form EIA-860.” Accessed May 6, 2018.

https://www.eia.gov/electricity/generatorcosts/.

xlv EIA, “Operating Expenses data.” Accessed May 6, 2018.

https://www.eia.gov/electricity/annual/html/epa_08_04.html.

${ }^{\text {xlvi }}$ Bhattacharyya, Subhes C., and Debajit Palit. "Mini-Grid Based off-Grid Electrification to Enhance Electricity Access in Developing Countries. (2016). 
Page 24 of 24- Word Count: 4,844

xlvii Offgrid Electric got funded by SolarCity and venture capital investors. SolarCity launched residential solar market in the US by offering solar systems on lease to customers happy to pay monthly power payments.

xlviii Sivaram, Varun, “Taming the Sun” Innovations to Harness Solar Energy and Power the Planet. The MIT Press. 2018

${ }^{x l i x}$ Haas, R., W. Eichhammer, C. Huber, O. Langniss, A. Lorenzoni, R. Madlener, P. Menanteau, et al. "How to Promote Renewable Energy Systems Successfully and Effectively.” Energy Policy 32, no. 6 (April 1, 2004): 83339. https://doi.org/10.1016/S0301-4215(02)00337-3.

Harrison, Blake, "Expanding the Renewable Energy Industry Through Tax Subsidies.” University of Michigan Journal of Law Reform. Volume 48. Issue 3. (2015)Accessed May 6, 2018. https://repository.law.umich.edu/cgi/viewcontent.cgi?article=1137\&context=mjlr.

lMinistry of Planning, Development \& Reform, GOP “Pakistan 2025-One Nation, One Vision.” Accessed April 28, 2018. http://epd.punjab.gov.pk/system/files/Section-1\%20\%28Introduction\%29\%20and\%20Section-

$2 \% 20 \% 28$ Legal\%20\%20Framework\%29.pdf.

li According to the World Bank, $97 \%$ of the population had access to electricity in 2017 compared to $47 \%$ of the population in 1990

World Bank, “Access to Electricity (\% of Population) | Data.” Accessed March 04, 2018. https://data.worldbank.org/indicator/EG.ELC.ACCS.ZS.

I highly doubt this figure. As per the most recent census, Pakistan has a population of 207 million spread over 32.2 million households in 2017. According to Pakistan Economic Survey, the average household size is 6.45. From Power system statistics, there are 22.8 million domestic connection across country. Thus, electricity access rate is $70.8 \%$.

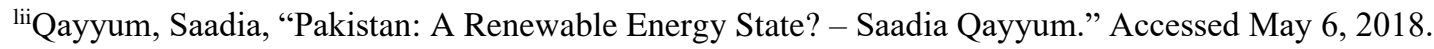
https://saadiaqayyum.wordpress.com/2016/10/07/achieving-universal-energy-access-in-pakistan/.

liii “NEPRA State of Industry Report 2016.” Accessed May 6, 2018. http://www.nepra.org.pk/Publications/State\%20of\%20Industry\%20Reports/NEPRA\%20State $\% 20$ of $\% 20$ Industry $\% 2$ 0Report\%202016.pdf.

Among the provinces, Sindh has the highest number $(13,541)$ of un-electrified villages, followed by Punjab $(7,432)$, KPK $(5,927)$ and Balochistan $(5,802)$. On the other hand, Azad Jammu and Kashmir (AJK) and Gilgit-Baltistan have more than $90 \%$ electrification.

${ }^{\text {liv }}$ https://www.business-standard.com/article/current-affairs/23-mn-homes-in-villages-still-without-power-17-don-thave-drinking-water-

118082900140_1.html\#: :text=Of\%20640\%2C932\%20villages\%20in\%20India,rural\%20areas\%20are\%20without $\% 20$ electricity.

lv A World Bank report states: In 2014, total installed capacity was 24,900 MW (as per ministry of Water \& Power, the installed capacity in FY 2017 was about 25,000 MW) but a maximum of only about 16,700 MW was available, and of that about $4,700 \mathrm{MW}$ is only available during the summer when hydropower generation is at its maximum. As a result, the country has been facing a peak shortfall between 5000-7000 MW since 2010. In consequence, load shedding has become the norm at 6-8 hours a day for households and 1-2 hours a day for the industry, hurting all economic sectors and people's lives and livelihoods. 
Page 25 of 24- Word Count: 4,844

World Bank, "Project Information Document.” Report No.: PIDC54374. March 2016. Accessed March 04, 2018. http://documents.worldbank.org/curated/en/468051468290145735/pdf/PID-Print P154987-03-10-20161457608511302.pdf.

${ }^{\text {lvi }}$ Hydropower is good; however, the problem is that it is subject to the vagaries of nature. Hydropower generation is at its peak in the summer. Moreover, there is a lot of political backlash to the construction of new water dams

lvii Share in electricity generation: Thermal- $64 \%$, Hydro- $30 \%$, and Nuclear- $6 \%$

"Energy." Chapter 14. Accessed March 4, 2018. http://www.finance.gov.pk/survey/chapters_17/14-Energy.pdf

lviii Pakistan's dependence on oil import is $24 \%$, compared to compared to India's $18 \%$ and Bangladesh's $21 \%$ “Energy Sector Assessment for USAID/Pakistan.” Accessed March 4, 2018.

http://pdf.usaid.gov/pdf_docs/Pnadn955.pdf

lix Aziz S, Pasha H. State of the Economy-Emerging From Crisis 2008.Beacon House National University publication; 2008.

World Bank. Corporation IF. Enterprise Surveys-Pakistan.; 2007.

Mirza UK, Maroto-Valer MM, Ahmad N. Status and outlook of solar energy use in Pakistan. Renewable and Sustainable Energy Reviews 2003; 7:501-14.

Sheikh MA. Energy and renewable energy scenario of Pakistan. Renewable \& Sustainable Energy Reviews 2010; 14

Sahir MH, Qureshi AH. Assessment of new and renewable energy resources potential and identification of barriers to their significant utilization in Pakistan. Renewable and Sustainable Energy Reviews 2008; 12:290-8.

In all the above-mentioned studies, authors talk about the high renewable energy potential of Pakistan. They also broadly summarize the potential, institutional setups, various social barriers, market-related barriers, and policy shortcomings. Moreover, the studies identify technological barriers as one of the prime deterrents for the PV growth.

${ }^{1 x}$ Rafique MM, Rehman S. "National Energy Scenario of Pakistan - Current Status, Future Alternatives, and Institutional Infrastructure: An Overview." Renewable and Sustainable Energy Reviews 69, 2017; 156-67. https://doi.org/10.1016/j.rser.2016.11.057.

Also see footnote 5. 